\title{
Vinyl Ether Oligomers with Conjugated-Polyene and Acetal Terminals: A New Chain-Transfer Mechanism for Cationic Polymerization of Vinyl Ethers
}

\author{
Sadahito AOSHIMA and Toshinobu HIgASHIMURA \\ Department of Polymer Chemistry, Kyoto University, \\ Kyoto 606, Japan
}

(Received December 8, 1983)

\begin{abstract}
Cationic oligomerizations of isobutyl vinyl ether (IBVE) and 2-chloroethyl vinyl ether (CEVE) were carried out with various initiators $\left(\mathrm{BF}_{3} \mathrm{OEt}_{2}, \mathrm{I}_{2}, \mathrm{CF}_{3} \mathrm{SO}_{3} \mathrm{H}, \mathrm{CH}_{3} \mathrm{SO}_{3} \mathrm{H}\right.$, and $\mathrm{CH}_{3} \mathrm{COClO}_{4}$ ) in benzene at $70^{\circ} \mathrm{C}$, and the structure and molecular weight distribution of the products were investigated. The oligomers obtained were constituted of oligo(vinyl ether)s with a conjugated polyene (I) or an acetal (II) terminal. To account for the formation of I and II, a new chain-transfer mechanism has been proposed, which involves successive dealcoholation from the growing chain to give polyene I and a reaction of the released alcohol with the growing vinyl ether cation to yield acetal-capped oligomers II. Oxo acid initiators $\left(\mathrm{CH}_{3} \mathrm{SO}_{3} \mathrm{H}, \mathrm{CF}_{3} \mathrm{SO}_{3} \mathrm{H}\right.$, and $\mathrm{CH}_{3} \mathrm{COClO}_{4}$ ) induced the dealcoholation more than $\mathrm{BF}_{3} \mathrm{OEt}_{2}$ or iodine, giving higher yields of $\mathrm{I}$. It was also demonstrated that the polyene and acetal terminal are formed not only in the oligomerization at high temperatures but also in the polymerization at around $0^{\circ} \mathrm{C}$. Thus the coloration of reaction mixtures in vinyl ether polymerization has now been interpreted by the formation of polyenes I.
\end{abstract}

KEY WORDS Cationic Oligomerization / Cationic Polymerization / ChainTransfer Reactions / 2-Chloroethyl Vinyl Ether / Isobutyl Vinyl Ether / Oxo Acids / End Group / Conjugated Polyene / Acetal / UV-Visible Spectra /

Vinyl ethers are typical monomers cationically polymerizable by various acidic initiators. ${ }^{1}$ Their polymerization behavior has been investigated in detail; the classical studies by Eley et $a .^{2}$ (kinetics) and Schildknecht et $a l^{3}$ (stereochemistry) were performed as early as in 1940's. More recently, we have reported "living" vinyl ether polymerization that lead to nearly monodisperse polymers. ${ }^{4}$

In spite of the accumulated studies, vinyl ether polymerization is known to show peculiar, still uninterpreted phenomena ${ }^{1}$ such as the coloration of reaction mixtures (typically starting from tint yellow through green to dark violet) and sometimes the polymers (yellowish) isolated therefrom. These phenomena are apparently related to chain-transfer and termination processes, but they have been studied much less than initiation and propagation reactions. In particular, few investigations have concerned the spectroscopic analysis of polymer endgroups that should directly reflect chain-transfer and termination mechanisms.

Equations $1-3$ illustrate the three chaintransfer mechanisms thus far proposed for vinyl ether polymerization, including direct proton transfer from the growing chain (eq 1), cleavage of the terminal ether bond in the propagating species via an oxonium-ion intermediate (eq 2), ${ }^{5}$ and a back-biting reaction via a cyclopropyl or six-membered cyclic intermediate (eq 3). ${ }^{6}$ These proposals are based on rather indirect evidence such as relative transfer constants $\left(k_{\mathrm{tr}} / k_{\mathrm{p}}\right)$ and the steric structure of polymers. Reaction 2 has been proposed to account for the presence of an olefinic 

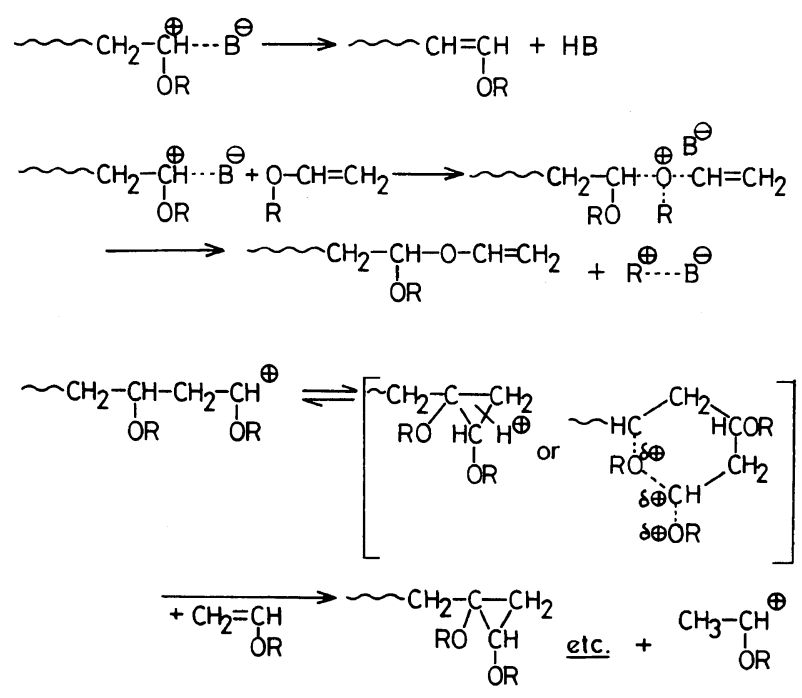

endgroup (determined by bromination) and the formation of an aldehyde on hydrolysis of product polymers; the amount of them increased with increasing $k_{\mathrm{tr}} / k_{\mathrm{p}}$. None of the mechanisms, however, can explain consistently all the characteristics of vinyl ether polymerization, particularly the coloration of reaction mixtures and resulting polymers.

This work aims to elucidate the chaintransfer reactions in cationic polymerization of vinyl ethers and in turn to synthesize new vinyl ether oligomers by controlled chain transfer. Thus, the oligomerizations of 2-chlorethyl and isobutyl vinyl ethers, as models for their polymerizations, were carried out at $70^{\circ} \mathrm{C}$.

\section{EXPERIMENTAL}

\section{Materials}

Commercial isobutyl vinyl ether (IBVE) and 2-chloroethyl vinyl ether (CEVE) were washed with an aqueous alkaline solution and then with water, dried overnight with anhydrous sodium sulfate, and distilled twice over sodium metal (for IBVE) or calcium hydride (for CEVE) before use. Acetyl perchlorate $\left(\mathrm{AcClO}_{4}\right)$ was synthesized as described elsewhere. ${ }^{7} \quad \mathrm{BF}_{3} \mathrm{OEt}_{2}$ and $\mathrm{CH}_{3} \mathrm{SO}_{3} \mathrm{H}$ (Wako Chemicals) were purified by distillation under reduced pressure. Iodine (Merck) and $\mathrm{CF}_{3} \mathrm{SO}_{3} \mathrm{H}$ (Wako Chemicals), both guaranteed reagents, were used without further purification. Solvents and the internal standard $\left(\mathrm{C}_{6} \mathrm{H}_{5} \mathrm{Cl}\right)$ for gas chromatography were purified as described ${ }^{8}$ and were distilled over $\mathrm{CaH}_{2}$ at least twice before use.

Acetaldehyde bis-2-chloroethyl and bisisobutyl acetals, as model compounds for structural analysis, were prepared by the reaction of acetaldehyde with the corresponding alcohols ( 2 equiv. to the aldehyde) in the presence of hydrochloric acid and calcium chloride as the dehydrating agent. ${ }^{9}$

\section{Oligomerization}

Oligomerization was carried out in an Erlenmeyer flask equipped with a three-way stop-cock under dry nitrogen. The concentration of water in the reaction mixture was smaller than $0.5 \mathrm{mmoll}^{-1}$. The reaction was initiated by adding a initiator solution with a syringe to a monomer solution and, after a certain period, stopped by adding methanol containing a small amount of aqueous ammonia. Conversion was determined by measuring the residual monomer concentration by gas chromatography with chlorobenzene as the internal standard. The reaction solu- 
tion after quenching was washed with a dilute aqueous alkaline solution (or with an aqueous sodium thiosulfate solution for iodine) to remove the catalyst residue, and the products were recovered from the organic layer by evaporation of the unreacted monomer and solvent under reduced pressure.

\section{Characterization}

The apparent molecular weight distribution (MWD) of the product was determined by highperformance liquid chromatography (HPLC; a JASCO TRIROTAR chromatograph with a JSP-101 polystyrene gel column, $20 \mathrm{~mm}$ i.d. $\times 500 \mathrm{~mm} ; \mathrm{CHCl}_{3}$ eluent). A dual-mode [UV-visible and refractive index (RI)] detection was applied. The molecular weight of poly(vinyl ether)s was approximately assessed from that of polystyrene of the same elution volume. When necessary, fractions containing dimers to octamers were separated from the product by preparative, recycling HPLC on the same instrument. The structure of the product was determined by ${ }^{1} \mathrm{H}$ and ${ }^{13} \mathrm{C}$ NMR (JEOL JNM FX-90Q, $\mathrm{CDCl}_{3}$ ) and UV-visible (Shimadzu UV 190) spectroscopy.

\section{RESULTS AND DISCUSSION}

\section{Oligomerization of CEVE}

$M W D$ of Products. CEVE was oligomerized with various acid initiators [oxo acids and their derivative $\left(\mathrm{CF}_{3} \mathrm{SO}_{3} \mathrm{H}, \quad \mathrm{CH}_{3} \mathrm{SO}_{3} \mathrm{H}, \quad\right.$ and $\left.\mathrm{AcClO}_{4}\right)$, a halogen $\left(\mathrm{I}_{2}\right)$, and a metal halide $\left.\left(\mathrm{BF}_{3} \mathrm{OEt}_{2}\right)\right]$ in benzene at $70^{\circ} \mathrm{C}$ at a low monomer concentration $\left(0.05 \mathrm{moll}^{-1}\right)$. The oligomerizations by $\mathrm{I}_{2}$ and $\mathrm{CH}_{3} \mathrm{SO}_{3} \mathrm{H}$ proceeded at such a slow rate as to give $c a .80 \%$ conversion in several hours, whereas those by the stronger initiators $\left(\mathrm{CF}_{3} \mathrm{SO}_{3} \mathrm{H}, \mathrm{AcClO}_{4}\right.$, and $\mathrm{BF}_{3} \mathrm{OEt}_{2}$ ) were completed within a few to several tens min. In spite of this rate difference, yellow-brown oligomers $\left(\mathrm{MW}=2 \times 10^{2}\right.$ $2 \times 10^{3}$ ) and a small amount of an insoluble product were obtained in all cases.

Figure 1 shows the HPLC traces (MWD) of

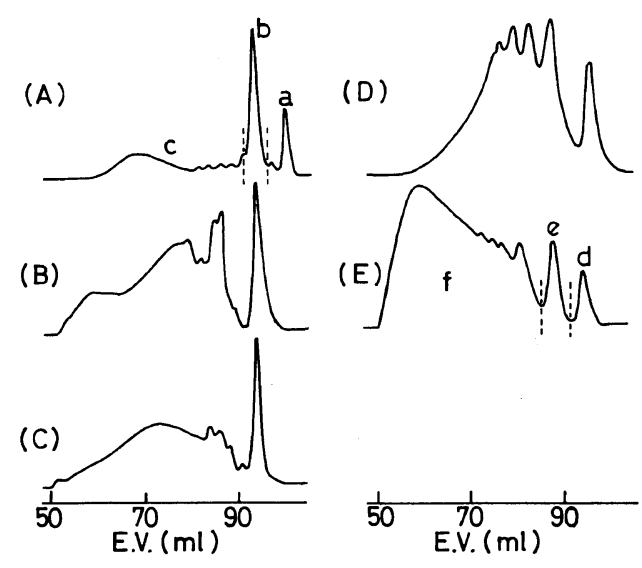

Figure 1. HPLC curves for CEVE oligomers obtained in benzene at $70^{\circ} \mathrm{C}:[\mathrm{M}]_{0}=0.05 \mathrm{moll}^{-1}$; initiator (mmoll 1-1). (A) $\mathrm{CH}_{3} \mathrm{SO}_{3} \mathrm{H}$ (1.0); (B) $\mathrm{AcClO}_{4}$ (0.05); (C) $\mathrm{CF}_{3} \mathrm{SO}_{3} \mathrm{H}$ (0.1); (D) $\mathrm{I}_{2}$ (5.0); (E) $\mathrm{BF}_{3} \mathrm{OEt}_{2}(0.2)$.

the oligomers (soluble part) obtained by these initiators. These traces do not show the actual MWD, because the refractive index of CEVE oligomers slightly increases with increasing molecular weights. The oxo-acid catalysts formed the oligomers having a main peak at elution volume $\sim 93 \mathrm{ml}$ (MW $\sim 200$; polystyrene calibration) coupled with a broad plateau extending to $\mathrm{MW} \sim 2 \times 10^{3}$ (Figures $1 \mathrm{~A}-$ C). This main peak notably increased in intensity with $\mathrm{CH}_{3} \mathrm{SO}_{3} \mathrm{H}$ (Figure 1A). On the other hand, $\mathrm{I}_{2}$ and $\mathrm{BF}_{3} \mathrm{OEt}_{2}$ gave the oligomers with higher molecular weights $(\mathrm{MW}=$ 1000-2000; Figures 1D and E).

\section{Structure of CEVE Oligomer Obtained with $\mathrm{CH}_{3} \mathrm{SO}_{3} \mathrm{H}$.}

(i) Characterization by NMR Spectroscopy. For structural analysis the oligomeric product obtained with $\mathrm{CH}_{3} \mathrm{SO}_{3} \mathrm{H}$ was fractionated into three fractions $\mathbf{a}-\mathbf{c}$ (shown in Figure 1A) by preparative HPLC. The ${ }^{1} \mathrm{H}$ NMR spectra of these fractions are shown in Figure 2.

The spectrum of fraction $\mathbf{a}$ is featured by the split peaks in the $\delta=5-7$ region, which are practically the same as those of trans-1alkoxy-1,3-butadienes (methoxy, ethoxy and 

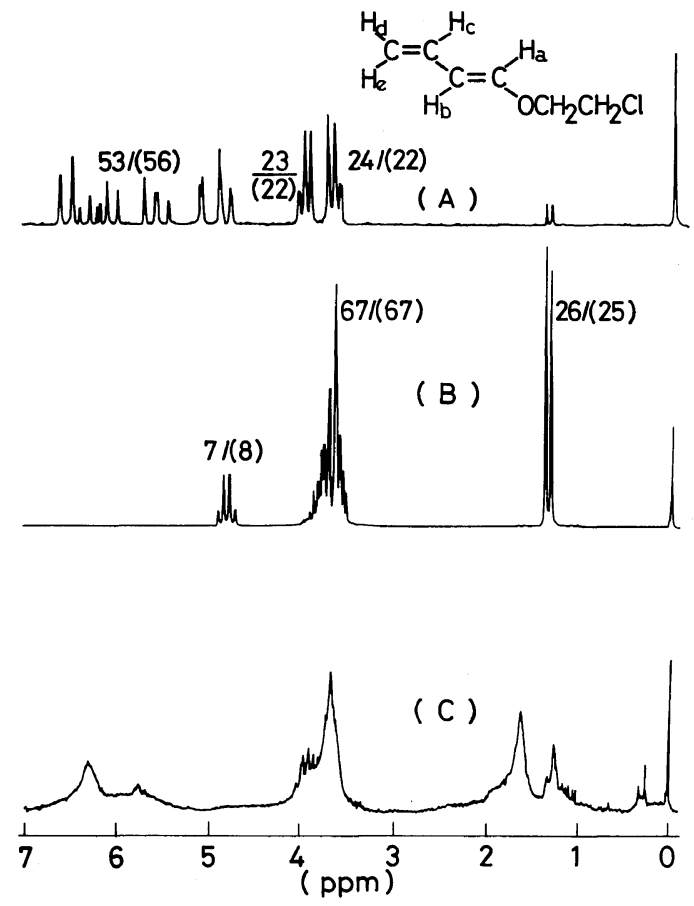

Figure 2. ${ }^{1} \mathrm{H}$ NMR spectra of fractions $\mathrm{a}-\mathrm{c}$ shown in Figure 1A: A, fraction $\mathbf{a}$; B, fraction $\mathbf{b}$; C, fraction $\mathbf{c}$.

isopropoxy). ${ }^{10}$ Thus fraction a was assigned to a trans-butadiene derivative with one chloroethyl group. Peak assignments are as follows: $\delta$ (ppm) $3.7\left(-\mathrm{CH}_{2} \mathrm{Cl}\right), 4.0\left(-\mathrm{OCH}_{2}-\right)$, and $4.8-6.7\left(\mathrm{CH}_{2}=\mathrm{CH}-\mathrm{CH}=\mathrm{CH}-; 4.9\left(\mathrm{H}_{\mathrm{d}}\right)\right.$, $5.0\left(\mathrm{H}_{\mathrm{e}}\right), 5.6\left(\mathrm{H}_{\mathrm{b}}\right), 6.2\left(\mathrm{H}_{\mathrm{c}}\right), 6.6\left(\mathrm{H}_{\mathrm{a}}\right) ; J_{\mathrm{ab}}=$ $13 \mathrm{~Hz}, \quad J_{\mathrm{bc}}=11 \mathrm{~Hz}, \quad J_{\mathrm{cd}}=11 \mathrm{~Hz}, J_{\mathrm{ce}}=17 \mathrm{~Hz}$, $J_{\mathrm{de}}=2 \mathrm{~Hz}$ ). Fraction b showed no unsaturated protons and its ${ }^{1} \mathrm{H}$ and ${ }^{13} \mathrm{C}$ NMR spectra were found identical with those of an acetal model, $\mathrm{CH}_{3} \mathrm{CH}\left(\mathrm{OCH}_{2} \mathrm{CH}_{2} \mathrm{Cl}\right)_{2}$. ${ }^{1} \mathrm{H}$ and ${ }^{13} \mathrm{C} \mathrm{NMR}$ peak assignments are as follows: ${ }^{1} \mathrm{H}$ NMR $\delta$ (ppm) $1.4\left(\mathrm{CH}_{3}-\right), 3.5-4.0\left(-\mathrm{OCH}_{2} \mathrm{CH}_{2} \mathrm{Cl}\right)$, and $4.9\left(-\mathrm{CH}_{\backslash}^{\prime}\right) ;{ }^{13} \mathrm{C} \mathrm{NMR} \delta(\mathrm{ppm}) 19.4(\mathrm{q}$, $\left.\mathrm{CH}_{3}-\right), 43.1\left(\mathrm{t},-\mathrm{CH}_{2} \mathrm{Cl}\right), 64.8\left(\mathrm{t},-\mathrm{OCH}_{2}-\right)$, and $99.9\left(\mathrm{~d},-\mathrm{CH}^{\prime}\right)$, (d, t, and $\mathrm{q}$ indicate peak multiplicity on off-resonance decoupling). The numbers in Figure 2 indicate the relative signal intensities in percent determined from peak areas; those in parentheses show the corresponding values based on the assigned structures. The agreement between the calculated
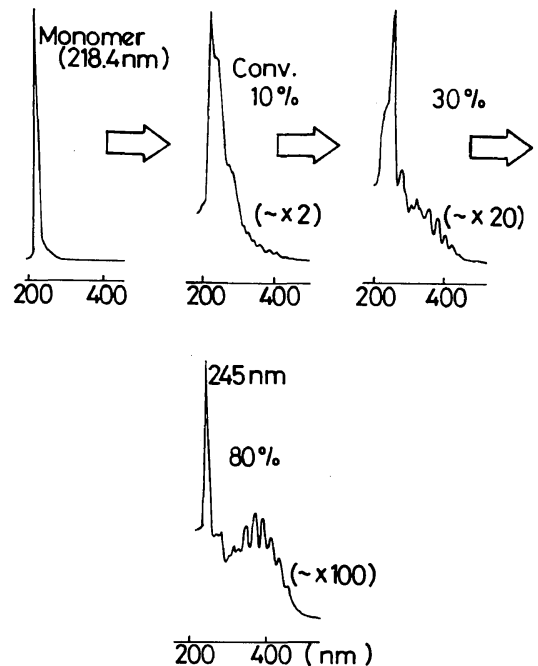

Figure 3. Conversion dependence of the UV-visible spectra of the CEVE oligomers obtained by $\mathrm{CH}_{3} \mathrm{SO}_{3} \mathrm{H}$ in benzene at $70^{\circ} \mathrm{C}\left([\mathrm{M}]_{0}=0.05 \mathrm{moll}^{-1}\right)$.

and observed values is satisfactory.

Comparison of Figure 2C with Figures 2A and $B$ indicates that fraction $\mathbf{c}$ consists of oligomers with a conjugated diene (or higher polyene) terminal; namely, spectrum 2C exhibits a broad multiplet in the region $\delta 5.3$ $6.6 \mathrm{ppm}$, assignable to $(\mathrm{CH}=\mathrm{CH})_{n}$, but no signals of an acetal methine proton $\left[-\mathrm{CH}\left(\mathrm{OCH}_{2} \mathrm{CH}_{2} \mathrm{Cl}\right)_{2}\right]$ at $\delta 4.9 \mathrm{ppm}$. Therefore, we concluded that the CEVE oligomerization by $\mathrm{CH}_{3} \mathrm{SO}_{3} \mathrm{H}$ leads to oligomers having a conjugated diene or higher conjugated polyene terminal (fractions a and c) together with an acetal, $\mathrm{CH}_{3} \mathrm{CH}\left(\mathrm{OCH}_{2} \mathrm{CH}_{2} \mathrm{Cl}\right)_{2}$ (fraction b), formed from the CEVE monomer.

(ii) Characterization by UV-Visible Spectroscopy. The formation of unsaturated (polyene) oligomers was confirmed by UVvisible spectroscopic analysis. Figure 3 shows the absorption spectra of a series of unfractionated oligomerization products obtained at different CEVE conversions. At each conversion, the product exhibited absorptions with a fine structure in the region 220$450 \mathrm{~nm}$. Interestingly, with increasing conversion the absorbance increased remarkably (by 


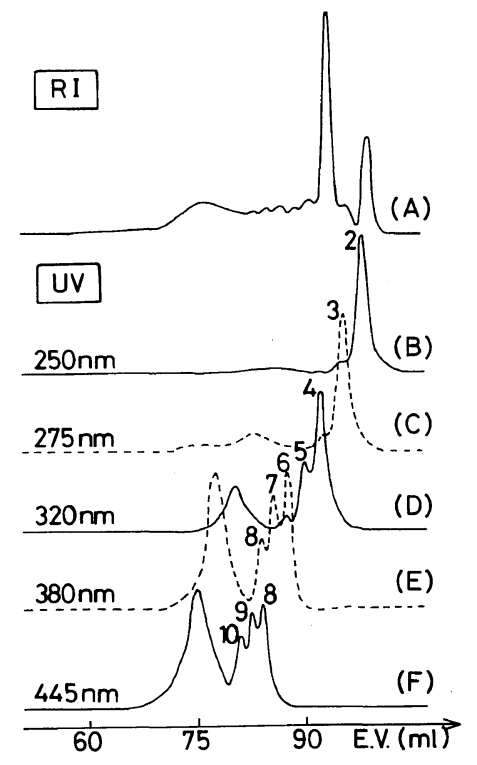

Figure 4. Dual-mode [UV-RI] HPLC traces for the CEVE oligomers obtained by $\mathrm{CH}_{3} \mathrm{SO}_{3} \mathrm{H}$ in benzene at $70^{\circ} \mathrm{C}\left([\mathrm{M}]_{0}=0.05 \mathrm{moll}^{-1}\right)$. UV traces were monitored at: (B) 250; (C) 275; (D) 320; (E) 380; (F) $445 \mathrm{~nm}$.

a factor of $10^{2}$ or more; see the magnification ratios indicated), and new bands emerged at longer wavelengths. Thus the product obtained at $100 \%$ conversion absorbed intensely in the visible region up to $c a .500 \mathrm{~nm}$.

Figure 4 illustrates the dual-mode [UV-RI] HPLC traces for the oligomer obtained with $\mathrm{CH}_{3} \mathrm{SO}_{3} \mathrm{H}$ (sample A in Figure 1). The RIdetector trace (Figure 4A) indicates the MWD of the whole product and is compared with a series of UV-detector traces monitored at various wavelengths (Figures $4 \mathrm{~B}-\mathrm{F}$ ). These HPLC spectra indicate that each oligomer fraction can be detected only at a specific wavelength which is longer for a higher oligomer. For instance, fraction $\mathbf{2}$ is detectable only at $250 \mathrm{~nm}$ (Figure 4B), whereas higher oligomers 8-10 should be monitored above $445 \mathrm{~nm}$ (Figure 4F). Therefore, the complicated UV spectra shown in Figure 3 are not due to one chromophore showing an absorption with a fine structure (e.g., compounds having aromatic moieties) but to nine or more unsaturated compounds (2-10) exhibiting

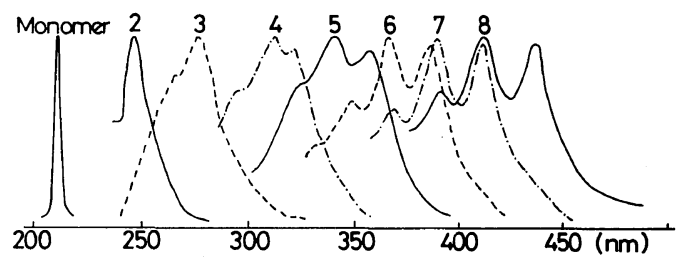

Figure 5. UV spectra of fractions $2-8$ shown in Figure 4.

different absorption maxima depending on their molecular weight.

The specific UV-visible detection of CEVE oligomers according to their molecular weight, in turn, enabled us to separate compounds 2 8 (Figure 4) by HPLC using a UV detector; note that this separation cannot be accomplished on a RI detector that will give only a poorly resolved eluogram (Figure 4A). Figure 5 shows the absorption spectra of fractions 2 8. Each fractionated product exhibits an absorption with a clear fine structure, the peak maximum of which increases progressively with increasing molecular weight. These phenomena are characteristic of conjugated polyenes (e.g., non-substituted, conjugated polyene; $\left.\mathrm{H}(\mathrm{CH}=\mathrm{CH})_{n} \mathrm{H}\right) \cdot{ }^{11}$ In addition, the spectrum of fraction 2 was the same as that of $\mathrm{CH}_{2}=\mathrm{CH}-\mathrm{CH}=\mathrm{CH}-\mathrm{OCH}_{2} \mathrm{CH}_{2} \mathrm{Cl}$ (fraction $\mathbf{a}$ in Figure 1; see above). All these facts indicate that the unsaturated oligomers (e.g., 2-10) obtained by $\mathrm{CH}_{3} \mathrm{SO}_{3} \mathrm{H}$ are conjugated polyenes $\mathrm{I}\left(\mathrm{R}=\mathrm{CH}_{2} \mathrm{CH}_{2} \mathrm{Cl}, \mathrm{R}^{\prime}=\mathrm{H}\right.$; $n=2-10)$.

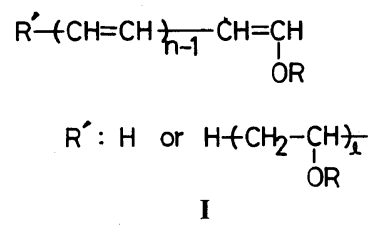

Another proof for conjugated polyene structure I was obtained by plotting the square of the absorption maximum wavelength $\left(\lambda_{\text {max }}^{2}\right)$ for fractions $2-\mathbf{8}$ against the number of their expected conjugated double bonds $(n)$ (Figure 6 , line a). The plot gave a straight line. It is known, both empirically ${ }^{12,13}$ and theoreti- 
cally, ${ }^{12,14}$ that such a linear $\lambda_{\max }^{2}-n$ relation holds for a homologous series of conjugated polyenes, e.g., $\left.\quad \mathrm{C}_{6} \mathrm{H}_{5}+\mathrm{CH}=\mathrm{CH}\right)_{n} \mathrm{C}_{6} \mathrm{H}_{5}$ (Figure 6, line b) and $\mathrm{H}-(\mathrm{CH}=\mathrm{CH})_{n} \mathrm{H}$ (Figure 6, line c). ${ }^{12,13}$ Taking into account minor effects of the terminal alkoxyl group, the close overlap of plots $a$ and $c$ further confirms structure I for the CEVE oligomers obtained with $\mathrm{CH}_{3} \mathrm{SO}_{3} \mathrm{H}$.

(iii) Interpretation of the Coloration during Oligomerization. When conjugated polyenes

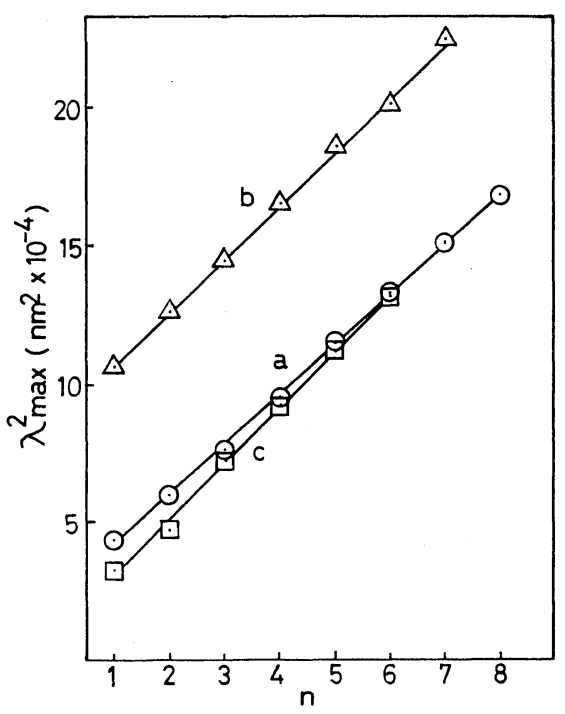

Figure 6. Relationships between $\lambda^{2}$ max , the square of absorption maximum wavelength, and $n$, the number of conjugated double bonds: (O) $\mathrm{H}(\mathrm{CH}=\mathrm{CH})_{n}$ $\mathrm{OCH}_{2} \mathrm{CH}_{2} \mathrm{Cl}$ (2-8 in Figure 4); $(\triangle) \mathrm{C}_{6} \mathrm{H}_{5}+\mathrm{CH}=$ $\mathrm{CH})_{n} \mathrm{C}_{6} \mathrm{H}_{5} ;(\square) \mathrm{H}(\mathrm{CH}=\mathrm{CH})_{n} \mathrm{H}^{10,11}$ are protonated with an acid, their UV-visible absorptions exhibit a large bathochromic shift to the visible region. ${ }^{15}$ We thus studied protonation (re-acidification) and subsequent neutralization of the CEVE oligomers to find out conclusive evidence for structure I (Figure 7). A CEVE oligomer solution obtained by $\mathrm{CF}_{3} \mathrm{SO}_{3} \mathrm{H}$ in benzene shows absorptions extending from 300 to $400 \mathrm{~nm}$ (Figure 7A). When a small amount of $\mathrm{CF}_{3} \mathrm{SO}_{3} \mathrm{H}$ was added to this yellow solution, it immediately turned black and, correspondingly, its absorption spectrum exhibited a new broad band in the visible region above $450 \mathrm{~nm}$, while the peak near $350 \mathrm{~nm}$ in turn decreased in intensity (Figure 7B). Neutralization of this solution with ammoniacal methanol regenerated a yellow solution; the flat band around $600 \mathrm{~nm}$ completely disappeared and the $350 \mathrm{~nm}$ peak increased (Figure 7C). These series of color and spectral changes indicate that the coloration of a polymerizing solution of vinyl ethers, as often observed, is due to the protonation of the polyene terminals formed during the polymerization.

Separate experiments showed that, when brominated in $\mathrm{CHCl}_{3}$ at room temperature, the yellowish CEVE oligomer turns colorless, again supporting its polyene structure.

Effects of Initiators on Oligomer Structure. A sample of the CEVE oligomers obtained with a metal halide $\left(\mathrm{BF}_{3} \mathrm{OEt}_{2}\right)$ was fractionated by
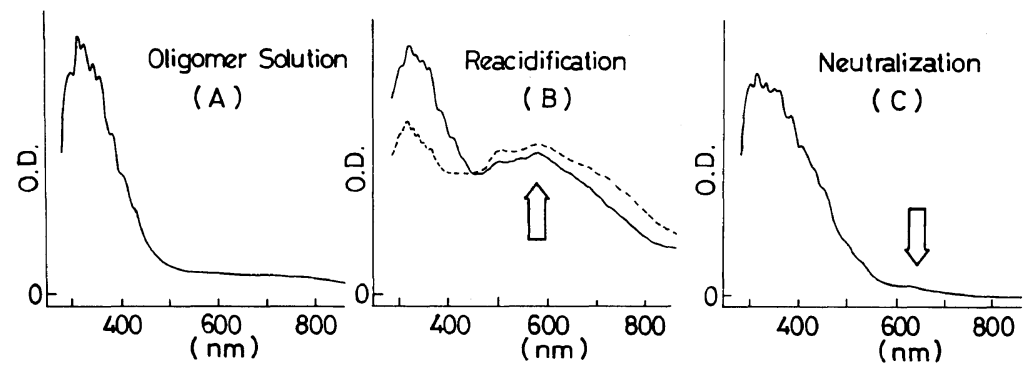

Figure 7. Changes in the UV-visible spectrum of the $\mathrm{CEVE}$ oligomers obtained by $\mathrm{CF}_{3} \mathrm{SO}_{3} \mathrm{H}$ in benzene at room temperature $\left([\mathrm{CEVE}]_{0}=0.5 \mathrm{mmoll}^{-1} ;\left[\mathrm{CF}_{3} \mathrm{SO}_{3} \mathrm{H}\right]=2.5 \mu \mathrm{moll}^{-1}\right)$. (A), oligomer solution, yellow; (B), after re-acidification to give $\left[\mathrm{CF}_{3} \mathrm{SO}_{3} \mathrm{H}\right] /[\mathrm{CEVE}]_{0}=0.03(-), 0.06(---)$, black; (C), after neutralization with ammoniacal methanol, yellow. 
HPLC into fractions $d$ to $f$ shown in Figure 1E. With this initiator no insoluble material was formed. Typical ${ }^{1} \mathrm{H}$ NMR spectra of these fractions are shown in Figure 8. The lowest<smiles>[R]OC([R])CC([R])CC</smiles>

two fractions, $\mathbf{d}$ and $\mathbf{e}$, were found to be acetaltype compounds II (d, $m=1 ; \mathrm{e}, m=2)$. Oligomer part $\mathbf{f}$ (Figure $8 \mathrm{C}$ ) showed signals of both polyene $(\delta 5-6.7 \mathrm{ppm})$ and acetal $(\delta \sim 4.9 \mathrm{ppm})$ terminals. This indicates that $\mathrm{BF}_{3} \mathrm{OEt}_{2}$ produces not only polyenes $\mathbf{I}$ but acetal-terminated oligomers II $(m \geq 3)$ which, in contrast, could not be detected in ${ }^{1} \mathrm{H}$ NMR of oligomers with $\mathrm{CH}_{3} \mathrm{SO}_{3} \mathrm{H}$ in Figure 2 (see above). Interestingly, the butadiene derivative $\mathrm{CH}_{2}=\mathrm{CH}-\mathrm{CH}=\mathrm{CH}-\mathrm{OCH}_{2} \mathrm{CH}_{2} \mathrm{Cl} \quad(\mathrm{I}, n=2)$ did not form in the presence of $\mathrm{BF}_{3} \mathrm{OEt}_{2}$. A halogen $\left(\mathrm{I}_{2}\right)$ was also used, and it gave similar qualitative results as $\mathrm{BF}_{3} \mathrm{OEt}_{2}$.

Since $\mathrm{BF}_{3} \mathrm{OEt}_{2}$ gave the completely soluble product, the relative amounts of the polyeneand acetal-capped oligomers could be determined by ${ }^{1} \mathrm{H}$ NMR (Table I). Table I also lists the ratio of monomeric $(m=1)$ to oligomeric $(m \geq 2)$ homologs of II for $\mathrm{CH}_{3} \mathrm{SO}_{3} \mathrm{H}$ and $\mathrm{CH}_{3} \mathrm{COClO}_{4}$; the amount of polyene-capped oligomers could not be obtained, since these oxo acids yielded partly insoluble products.

Although the amount of polyenes I was not quantitatively determined, the oxo acid initiators $\left(\mathrm{CH}_{3} \mathrm{SO}_{3} \mathrm{H}, \mathrm{CF}_{3} \mathrm{SO}_{3} \mathrm{H}\right.$, and $\left.\mathrm{AcClO}_{4}\right)$ obviously led to much more polyenes I $(n \geq 2)$ than a metal halide $\left(\mathrm{BF}_{3} \mathrm{OEt}_{2}\right)$ or a halogen $\left(\mathrm{I}_{2}\right)$. This suggests that these initiators promote the dealcoholation from the growing chain (see Scheme I below) by promoting the $\beta$-proton elimination or migration through their nucleophilic, oxygen-containing counter-anions, as we pointed out previously. ${ }^{16}$

\section{Oligomerization of IBVE}

As a vinyl ether other than CEVE and free of hetero atoms, IBVE was oligomerized with

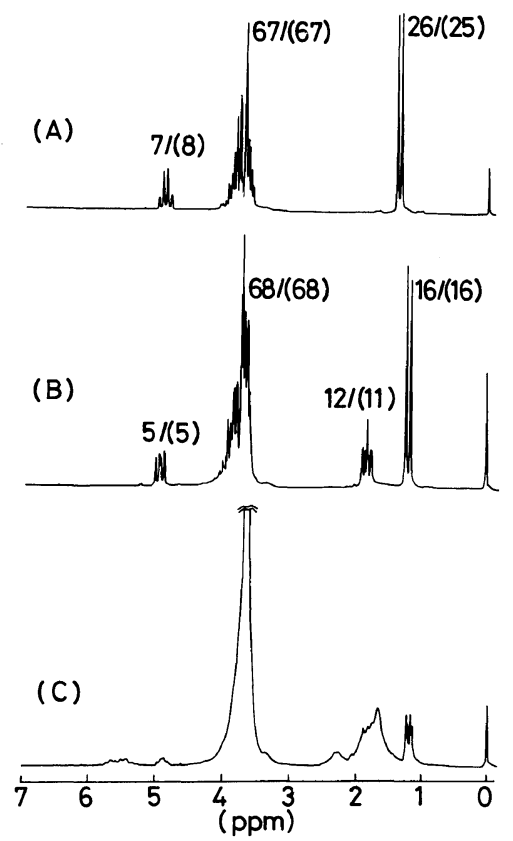

Figure 8. ${ }^{1} \mathrm{H}$ NMR spectra of (A) fraction d shown in Figure 1E; (B) fraction $\mathbf{e}$; (C) fraction $\mathbf{f}$.

Table I. Structure of CEVE oligomers obtained with different initiators in benzene at $70^{\circ} \mathrm{C}^{\mathrm{a}}$

\begin{tabular}{lccc}
\hline Cat. & $\mathrm{CH}_{3}-\mathrm{CH}_{\succ \mathrm{OR}}^{\prime \mathrm{OR}}$ & $\left.\mathrm{H}+\mathrm{CH}_{2}-\underset{\mathrm{OR}}{\mathrm{CH}}\right)_{m-1} \mathrm{CH}_{2}-\mathrm{CH}_{\backslash \mathrm{OR}}^{\prime}$ & $+\mathrm{OR}=\mathrm{CH})_{n}$ \\
\hline $\mathrm{BF}_{3} \mathrm{OEt}_{2}$ & $\sim 0.2$ & $\sim 0.3$ & $\sim 0.5$ \\
\hline $\begin{array}{l}\mathrm{CH}_{3} \mathrm{COClO}_{4} \\
\mathrm{CH}_{3} \mathrm{SO}_{3} \mathrm{H}\end{array}$ & $(\sim 0.7)$ & $(\sim 0.3)$ & n.d. $^{\mathrm{b}}$ \\
\hline
\end{tabular}

${ }^{a} \mathrm{~mol} \%$ determined by ${ }^{1} \mathrm{H}$ NMR.

b The amount of polyene could not be obtained because of yielding partly insoluble (cross-linked) products. 
oxo acids $\left(\mathrm{CF}_{3} \mathrm{SO}_{3} \mathrm{H}\right.$ and $\left.\mathrm{CH}_{3} \mathrm{SO}_{3} \mathrm{H}\right)$ in benzene at $70^{\circ} \mathrm{C}\left([\mathrm{IBVE}]_{0}=0.050-1.0 \mathrm{moll}^{-1}\right)$. Under these conditions, the reactions by the two initiators were completed within several min to yield a brown solid and a transparent yellowish liquid with a fragrance. The solid product was insoluble in all common organic solvents and presumably a crosslinked material formed from polyenes similar to $\mathbf{I}$.

The liquid (soluble) part showed a single, sharp peak at $\mathrm{MW} \sim 200$ (polystyrene calibration) on HPLC analysis. The ${ }^{1} \mathrm{H}$ and ${ }^{13} \mathrm{C}$ NMR spectra of this part were also identical with those of an authentic sample of an acetal [II, $\quad m=1 ; \quad \mathrm{R}=\mathrm{CH}_{2} \mathrm{CH}\left(\mathrm{CH}_{3}\right)_{2}, \quad\left(\mathrm{CH}_{3} \mathrm{CH}-\right.$ $\left.\left[\mathrm{OCH}_{2} \mathrm{CH}\left(\mathrm{CH}_{3}\right)_{2}\right]_{2}\right), \delta_{{ }_{1} \mathrm{HMR}}(\mathrm{ppm}) ; 0.9$ (d, $\left.-\mathrm{CH}\left(\mathrm{CH}_{3}\right)_{2}\right), 1.2\left(\mathrm{~d}, \mathrm{CH}_{3}-\mathrm{CH}_{\backslash}^{\prime}\right), 1.8$ (m, $\left.-\mathrm{OCH}_{2}-\mathrm{CH}^{\prime}\right), 3.2\left(\mathrm{~m},-\mathrm{O}-\mathrm{C}_{-}-\right.$), 4.7 (q, $\mathrm{CH}_{3}-$ $\left.\mathrm{CH}^{\prime}\right)$ ]. These data indicate that the oligomerizations of IBVE and CEVE by oxo acids are very similar in mechanism, both yielding monomeric acetals $(\mathbf{I I} ; m=1)$ and conjugated polyenes (I).

\section{Reaction of CEVE at low temperatures}

Polyene I and acetal-capped polymer II were found to form not only in oligomerization at high temperatures but also in polymerization of CEVE at low temperatures. The oligomerization was carried out with $\mathrm{CF}_{3} \mathrm{SO}_{3} \mathrm{H}$ in benzene at $0^{\circ} \mathrm{C}$ and a high CEVE concentration $\left(1.0 \mathrm{moll}^{-1}\right)$. Nearly $90 \%$ of the monomer was consumed within twenty minutes to give poly(CEVE) with $M_{w}=5.7 \times 10^{3}, M_{n}=$ $2.2 \times 10^{3}$ (by HPLC, polystyrene calibration).

Figure 9 shows the UV spectrum of the polymer. The bands with a fine structure seen in the visible region indicate the formation of various conjugated polyenes similar to $I$. Because of its higher molecular weight, the poly(CEVE) showed weaker polyene absorptions than the corresponding oligomers.

Figure 10 shows the ${ }^{1} \mathrm{H}$ NMR spectrum of the same polymer along with peak assignments. Similarly to the CEVE oligomers ( $c f$. Figure $8 \mathrm{C}$ ), the polymer exhibited signals of

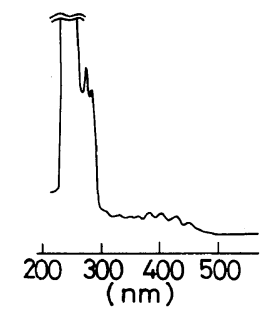

Figure 9. UV-visible spectrum of the CEVE polymer obtained by $\mathrm{CF}_{3} \mathrm{SO}_{3} \mathrm{H}$ in benzene at $0^{\circ} \mathrm{C}\left([\mathrm{M}]_{0}=1.0\right.$ moll $1^{-1}$ ).

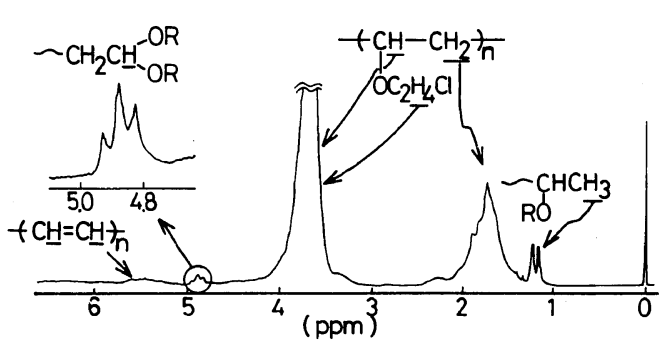

Figure 10. ${ }^{1} \mathrm{H}$ NMR spectrum of the CEVE polymer obtained by $\mathrm{CF}_{3} \mathrm{SO}_{3} \mathrm{H}$ in benzene at $0^{\circ} \mathrm{C}\left([\mathrm{M}]_{0}=1.0\right.$ moll $1^{-1}$ ).

both polyene $(\delta 5-6 \mathrm{ppm})$ and acetal $(\delta 4.9$ ppm, triplet) endgroups, along with the doublet at $\delta 1.2 \mathrm{ppm}$ due to the methyl "head" group $\left(\mathrm{CH}_{3} \mathrm{CH}(\mathrm{OR})-\right)$. These endgroup signals were not entirely due to oligomer fractions in the product, because its average molecular weight calculated on the basis of these peaks was in good agreement with the observed $M_{n}$. The ratio of the terminal methine (acetal) to the head methyl groups $\left(-\mathrm{CH}^{\prime} / \mathrm{CH}_{3}-\right)$ was 0.92 , indicating that at least $90 \%$ of the polymer is of acetal-capped structure II.

\section{Reaction Mechanism}

To account for the formation of the conjugated polyenes (I) and saturated oligomers (II) with an acetal terminal, we now propose the mechanism shown in Scheme I. In the first step, the propagating species III rearranges into oxonium ion $\mathbf{V}$ either via the direct migration of the $\beta$-proton to the penultimate ether oxygen or via the $\beta$-proton abstraction by the 


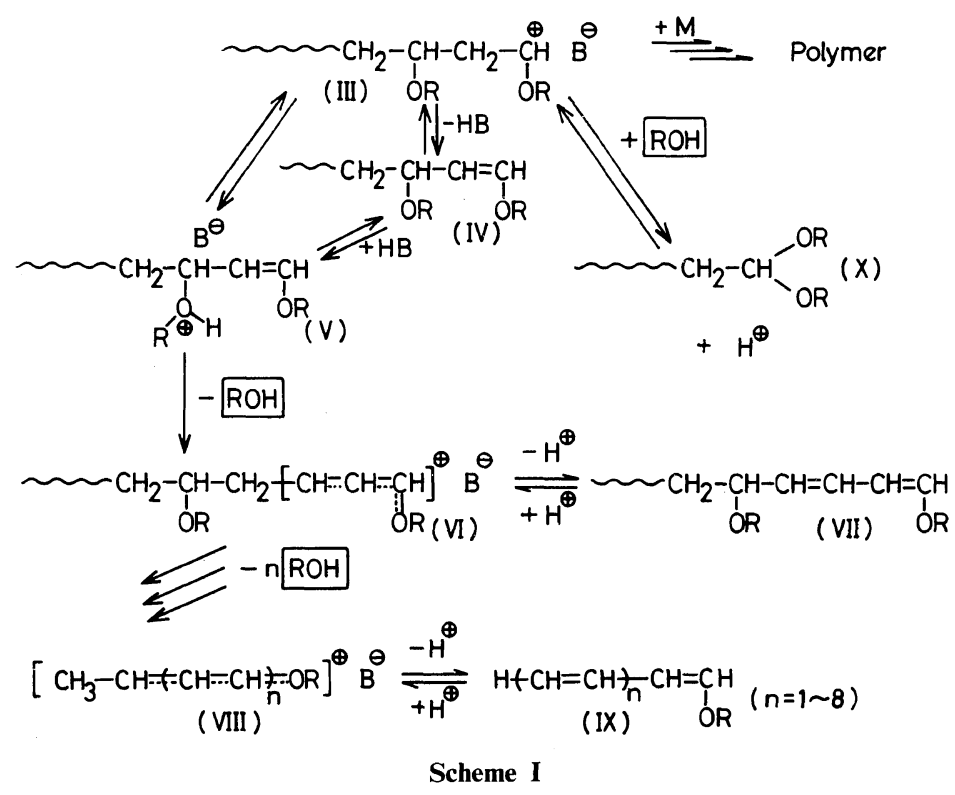

counter-anion (to give olefin IV) followed by protonation of the penultimate ether oxygen in IV. Intermediate $\mathbf{V}$ then releases an alcohol, resulting in conjugated carbocation VI. It is well-known that a protonated ether readily decomposes into an alcohol and a carbocation in an acidic medium

$$
\left(\mathrm{R}_{1}-\mathrm{O}-\mathrm{R}_{2}+\mathrm{H}^{\oplus} \rightleftarrows \mathrm{R}_{1}-\mathrm{O}^{\oplus}-\mathrm{R}_{2} \rightarrow \mathrm{R}_{1}^{\oplus}+\mathrm{R}_{2} \mathrm{OH}\right)
$$

The driving forces of this dealcoholation are a good leaving property of the alcohol and the generation of more delocalized (allylic) carbocation VI. Cation VI is in equilibrium with butadiene VII and both of them again release alcohol $\mathrm{ROH}$, by a mechanism similar to that for the transformation III $\rightarrow \mathbf{V} \rightarrow \mathbf{V I}$, to yield a cation with an extended conjugation. Such a successive dealcoholation from the propagating species (III) eventually leads to fully conjugated polyene cation VIII that yields polyene IX (or structure $I, R^{\prime}=\mathbf{H}$ ) via deprotonation.

Conjugated polyenes similar to IX have been reported to form during chemical modification of polymers, e.g., dehydrochlorination of $\mathrm{PVC}^{17}$ and dehydration of PVA. ${ }^{18}$
Although the polyene formation during polymerization does occur in some cases, e.g., by dehydrogeneration of polystyrene ${ }^{19}$ and poly(vinylfuran), ${ }^{20}$ that by dealcoholation from the growing species has not been known, except in the polymerization of ketene acetal ${ }^{21}$ where no details have been reported on the mechanism and product structure.

Scheme I also shows the pathway for acetalcapped polymer II. Thus the released alcohol $\mathrm{ROH}$, an effective transfer agent, readily reacts with the growing chain, and deprotonation from the resulting oxonium ion yields polymer X (II) with an acetal endgroup. The formation of an alcohol during polymerization takes place in the system $\mathrm{Et}_{3} \mathrm{O}^{+} \mathrm{SbCl}_{6}{ }^{-}$/alkyl vinyl ether/ $\mathrm{CH}_{2} \mathrm{Cl}_{2}$ as well, however, a different mechanism from ours has been proposed. ${ }^{22}$

The chain-transfer mechanism proposed in Scheme I seems to be unique for vinyl ethers that have an alkoxyl group, which is easy to be eliminated in an acidic environment. Such a pendant, a good leaving group, is not present in styrenes or alkenes.

Consequently, this work has shown that the color of produced polymers and reaction mixtures in vinyl ether polymerizations result 


\section{S. Aoshima and T. Higashimura}

from, respectively, conjugated polyene termini in the polymers and their protonated forms having different lengths.

Acknowledgement. We thank Dr. M. Sawamoto of this laboratory for helpful discussion.

\section{REFERENCES}

1. For reviews, see: (a) C. E. Schildnecht, "Vinyl and Related Polymers," John Wiley and Sons, New York, 1952, p 593.

(b) D. D. Eley, "The Chemistry of Cationic Polymerization," P. H. Plesch, Ed., Pergamon, Oxford, 1963, p 375.

(c) J. P. Kennedy and E. Maréchol, "Carbocationic Polymerization," Wiley, New York, 1982, p 192.

2. O. D. Eley and D. C. Pepper, Trans. Faraday Soc., 43, 112 (1947).

3. C. E. Schildnecht, A. O. Zoss, and C. McKinley, Ind. Eng. Chem., 39, 180 (1947); C. E. Schildnecht, S. T. Gross, and H. R. Davidson, ibid., 40, 2104 (1948).

4. M. Sawamoto, M. Miyamoto, and T. Higashimura, Macromolecules, in press.

5. Y. Imanishi, T. Higashimura, and S. Okamura, Kobunshi Kagaku, 19, 154 (1962).

6. C. E. H. Bawn, C. Fitzsimmous, A. Ledwith, J. Penfold, D. C. Sherington, and J. A. Weightman, Polymer, 119 (1971).
7. T. Masuda and T. Higashimura, J. Macromol. Sci., Chem., 5, 547 (1971).

8. H. Nishii and T. Higashimura, J. Polym. Sci., Polym. Chem. Ed., 15, 1179 (1977).

9. H. Adkins and B. H. Nissen, Org. Synth., Coll., 1, 1 (1941).

10. M. Otsuki, T. Masuda, and T. Higashimura, $J$. Polym. Sci., Polym. Chem. Ed., 14, 1157 (1976).

11. F. Sondheimer, D. A. Ben-Efraim, and R. Wolovsky, J. Am. Chem. Soc., 83, 1675 (1961).

12. G. N. Lewis and M. Calvin, Chem. Rev., 25, 273 (1939).

13. L. N. Ferguson, Chem. Rev., 43, 408 (1948).

14. (a) A. Maccoll, Quart. Rev., 1, 16 (1947).

(b) O. W. Adams and R. L. Miller, J. Am. Chem. Soc., 88, 404 (1966).

15. K. Hafner and H. Pelster, Angew. Chem., 73, 342 (1961).

16. T. Higashimura, M. Hiza, and H. Hasegawa, Macromolecules, 12, 1058 (1979).

17. For a review, see: M. Okawara, "Kobunshi no Kagakuhanno I," Kagakudojin, Kyoto, 1972.

18. A. Shindo and Y. Nakanishi, Nihon Kagakukaishi, 7, 1234 (1975).

19. A. Gandini and P. H. Plesch, Eur. Polym. J., 4, 55 (1968).

20. R. Alvarez, A. Gandini, and R. Martinez, Makromol. Chem., 183, 2399 (1982).

21. D. J. Dunn and P. H. Plesch, Makromol. Chem., 175, 2821 (1974).

22. D. D. Eley, D. F. Monk, and C. H. Rochester, J. Chem. Soc., Perkin Trans. 2, 1292 (1976). 